\title{
A CROSS SECTIONAL OBSERVATIONAL STUDY TO ASSESS THE SLEEP QUALITY AND PATTERNS, DURATION OF SLEEP RELATED SYMPTOMS, AND ACTION TAKEN BY THE PARTICIPANTS IN INDIAN CORPORATE OFFICES FOR INSOMNIA
}

\author{
Yardi N, Epileptology and Pediatric Neurology, KEM Hospital, Jehangir Hospital, \\ Deenanath Mangeshkar Hospital, Yardi Hospital, Pune, India \\ Peethambaran K, Pharmacology, Abbott India Ltd 3-4, Corporate Park, Sion-Trombay \\ Road, Mumbai 400071, India
}

Corresponding author: Kartik Peethambaran, MD Pharmacology, MBBS, Senior Medical Advisor Abbott India Ltd 3-4, Corporate Park, Sion-Trombay Road, Mumbai 400071, India, Tel: +91-22-71757460; Fax: 91-22-65978733; E-mail: kartik.peethambaran@abbott.com

Received: April 26, 2016; Accepted: July 06, 2016; Published: July 09, 2016

\begin{abstract}
Sleep-related problems in workers/employees in the corporate sector is common and needs due attention as these individuals are more prone to insomnia. The psychological job related stress factors such as interpersonal conflicts with fellow employees, job satisfaction, and social support were independently associated with a modestly increased risk of insomnia. Furthermore, the indirect cost due to insomnia in the form of absenteeism and lower work productivity are ten times higher than the direct cost of insomnia therapies.

Insomnia is generally associated with a host of negative consequences. The part analysis of this study showed that problems related to sleep significantly affect the quality of life in the form of estranged intimate relationships and impairs social functioning as well as leisure time activities. This study has helped to put an insight into the commonly reported sleep patterns among insomniac corporate office employees and a comparison with fellow participants without insomnia. Apart from reporting significant prevalence of undetected insomnia in day time Indian corporate employees, the study results highlight the fact that insomnia is majorly under reported to the primary physicians. Also, there is a significant decrease in the duration of sleep time and quality of sleep is poor in most of the insomniacs reporting "feeling of an unrefreshing sleep". There is an urgent need to impart knowledge about multidimensional treatment availability in insomniacs, which may help to improve their performance and overall quality of life. It is important to give appropriate attention to insomnia in corporate sector employees. In addition, primary care physicians should be encouraged to evaluate sleep as a norm in routine clinical practice.
\end{abstract}

\section{INTRODUCTION}

Sleep is a complex combination of physiological and behavioral processes ${ }^{1}$. According to the international classification of sleep disorders (ICSD-2), second edition, the person's condition can be diagnosed as insomnia if they have a predominant complaint of difficulty in sleep initiation, difficulty in sleep maintenance, or waking up too early, or sleep that is chronically unrestorative or poor in quality ${ }^{2}$. These difficulties should be present regardless of the availability of adequate opportunities and circumstances for sleep ${ }^{2}$. The patient should have at least one of the five complaints: (1) Fatigue or malaise, (2) Lack of attention, concentration, or memory 
impairment, (3) Daytime sleepiness, (4) Motivation, energy, or initiative reduction, or (5) Concern or worries about sleep ${ }^{2}$.

There is considerable individual variability in natural sleep patterns. Taken in a single period, most adults are comfortable with 6.5 to 8 hours of sleep daily ${ }^{3}$. The prevalence of insomnia in the general population is $9 \%{ }^{4}$ as reported by some international studies while apparently healthy population in South India reported a prevalence of $18.6 \%$. The wide variation in the reported prevalence rates of insomnia is due to differences in operational definitions of insomnia; populations studied, and research methodologies ${ }^{6}$. The prevalence of insomnia may be under-estimated as the rate of reporting insomnia to physicians is low ${ }^{7}$. Generally, patients take no action to alleviate their symptoms despite poor sleep impacting their quality of life ${ }^{7}$. Even when patients seek consultation; insomnia remains undertreated by the physicians ${ }^{8}$.

The etiology and pathophysiology of insomnia involves genetic, environmental, behavioral, and physiological factors culminating in hyperarousal ${ }^{8}$. Insomnia represents an important healthcare challenge as it may cause a considerable impact on the quality of life and impose burden on patients ${ }^{7}$. Insomnia is associated with significant psychological, medical, and economic burden ${ }^{6}$. The National Ambulatory Medical Care Survey (an annual population based national survey of US office-based physician visits) revealed that a growing awareness of insomnia and other sleep disorders led to a doubling of physician visits for sleeplessness from 1993 to 2007. Also, the diagnoses of insomnia increase 7-fold during this period ${ }^{9}$. Sleep-related problems in workers/employees in the corporate sector is common and needs due attention as these individuals are more prone to insomnia ${ }^{10,11}$. The psychological job-related stress factors such as interpersonal conflicts with fellow employees, job satisfaction, and social support were independently associated with a modestly increased risk of insomnia ${ }^{12}$. Furthermore, the indirect cost due to insomnia in the form of absenteeism and lower work productivity are ten times higher than the direct cost of insomnia therapies ${ }^{13}$.

\section{MATERIALS AND METHODS Study population and design}

This study was a cross sectional, observational study to determine the prevalence of insomnia amongst Indian corporate employees (The Spice study). The part analysis of this study (CTRI/2013/05/003671) has been reported in a separate publication ${ }^{13}$. This study was conducted in Indian corporate employees working for approximately 8 hours a day and aged 18 years and above ${ }^{14}$. Employees working in shift duties were excluded as shift rotations can impair an individual's circadian rhythm related functions ${ }^{15}$. This exclusion helped to comprehend the prevalence and sleep patterns of insomnia in daytime corporate employees more effectively. Six Indian corporate offices were identified and selected after they provided an authorization letter/ Memorandum of Understanding for participation. The respective human resource teams sent an introductory email describing the nature and objectives of this questionnaire based survey (to be self-completed by the participants) to all the employees. In addition, posters and banners were displayed, pamphlets were distributed, and employees were requested to nominate themselves to participate in the survey conducted at their office premises. The entire study process and the materials used for the study were approved by an Independent Ethics Committee. The participants signed the participant authorization form as a documentation of voluntary participation in the study.

The 'execution team' at each study site consisted of two field physicians and two clinical research coordinators, who explained the study and the contents of the questionnaires to the participants. The participants answered the participant reported outcome (PRO) questionnaire. Participants who did not have insomnia pre-diagnosed by a physician were requested to fill the Insomnia symptom questionnaire (ISQ). The field physician scored the completed ISQ and shared the score, its interpretation, and the questionnaire copy with the participants. The PRO data were couriered to the data management team for data entry and further statistical analysis. No investigational product was prescribed/administered to the participants during this study. 
In this study, we aimed to determine the sleep quality and patterns, duration of sleep-related symptoms, and action taken by the participants in Indian corporate offices for insomnia which has not been reported in previously conducted studies.

\section{QUESTIONNAIRES}

The PRO questionnaire captured general information of the participants such as demography, anthropometric measurements, marital status, and education. It also included questions related to the daily average working hours, current medical conditions (as diagnosed by their physician), personal habits (alcohol consumption, its type and quantity; smoking status, its frequency and duration; daily tea/coffee consumption), and the impact of insufficient sleep on day to day activities.

The ISQ is a 13 item self-rated questionnaire designed to identify insomnia based on the criteria that are consistent with the American Academy of Sleep Medicine's Research Diagnostic Criteria ${ }^{16}$. The ISQ items contain multiple choices on an ordinal scale to (1) determine the presence of a complaint of difficulty in initiating or maintaining sleep, or feeling that the sleep was non restorative or unrefreshing; (2) determine the frequency and duration of sleep complaints (questions 1 to 5) and duration of these symptoms (score choice is done on an ordinal scale ranging from $0=$ "never" to $5=$ "always"); and (3) assess the extent to which the individual's sleep complaints affect daytime activities, with response choices ranging from $0=$ "not at all" to 4="extremely" (Questions 6 to 13) ${ }^{17}$.

The ISQ scoring algorithm as described by Okun et al. results in a simple dichotomous outcome of insomnia ("present" or "absent"). Based on this algorithm, participants were assessed for the presence of insomnia ${ }^{17}$.

\section{STATISTICAL ANALYSIS}

Given the prevalence of insomnia in $10 \%$ of the general population ${ }^{18}$, a sample size of approximately 550 participants was arrived at. However, to increase the statistical power of the study, 605 participants were aimed to be enrolled. Descriptive statistics was used to summarize the data in this study. Frequencies and percentages were presented for categorical data. Sub group analysis was performed to analyze data on the basis of presence or absence of insomnia. Paired t test and chi square test were used to compare the continuous and the categorical variables, respectively.

\section{RESULTS}

A total of 606 participants were screened and 605 were enrolled in the study. Three participants were excluded from the analysis as they did not meet the eligibility criteria (worked in shift duties). The remaining 602 participants were included in the analysis set.

There was no difference in the demographic and anthropometric measures between participants with insomnia and those without insomnia (Table 1). The mean (standard deviation $\{$ SD $\}$ ) age of all the participants was $30.7( \pm 7.8)$ years and majority of the participants were males $(70.9 \%)$. The ratio of males to females was not significantly different in the group of participants with insomnia compared to those without insomnia. The marital status and educational qualification of the participants was similar in the two groups.

In part analysis of this study reported in a separate publication (CTRI/2013/05/003671), the prevalence of insomnia in these corporate employees was found to be $13.8 \%$ (83 of 602 participants) ${ }^{14}$. Of these, three participants were previously diagnosed with insomnia and were not required to answer the ISQ. The remaining 80 participants were detected with insomnia as assessed by the ISQ ${ }^{14}$. Based on the duration of sleep; a greater percentage of the participants with insomnia had less than 5 hours of sleep as compared to those without 


\begin{tabular}{|c|c|c|c|c|}
\hline \multicolumn{5}{|c|}{$\begin{array}{c}\text { Table } 1 \\
\text { Demographic and anthropometric data of participants. }\end{array}$} \\
\hline \multirow{2}{*}{ Variables } & $\begin{array}{l}\text { All participants } \\
(\mathrm{N}=602)\end{array}$ & $\begin{array}{l}\text { With insomnia } \\
\qquad(\mathrm{N}=83)\end{array}$ & $\begin{array}{l}\text { Without insomnia } \\
\qquad(\mathrm{N}=519)\end{array}$ & \multirow{2}{*}{ p-value } \\
\hline & Mean \pm SD & Mean \pm SD & Mean \pm SD & \\
\hline Age (years) & $30.7 \pm 7.8$ & $31.7 \pm 8.6$ & $30.5 \pm 7.6$ & 0.1170 \\
\hline Weight (kg) & $69.1 \pm 12.2$ & $68.4 \pm 11.0$ & $69.2 \pm 12.4$ & 0.1982 \\
\hline Height (cm) & $167.4 \pm 9.3^{*}$ & $165.7 \pm 8.9$ & $167.6 \pm 9.3$ & 0.2069 \\
\hline BMI $\left(\mathrm{kg} / \mathrm{m}^{2}\right)$ & $24.6 \pm 3.7^{*}$ & $24.6 \pm 3.8$ & $24.9 \pm 3.7$ & 0.6703 \\
\hline \multicolumn{5}{|c|}{ Gender $\mathrm{n}(\%)$} \\
\hline Male & $427(70.9 \%)$ & $55(66.3 \%)$ & $372(71.7 \%)$ & \multirow{2}{*}{0.3134} \\
\hline Female & $175(29.1 \%)$ & $28(33.7 \%)$ & $147(28.3 \%)$ & \\
\hline \multicolumn{5}{|c|}{ Marital status n (\%) } \\
\hline Married & $301(50.00 \%)$ & $42(50.60 \%)$ & $259(49.90 \%)$ & \multirow{3}{*}{0.3237} \\
\hline Unmarried & $299(49.70 \%)$ & $40(48.20 \%)$ & $259(49.90 \%)$ & \\
\hline Other $^{\dagger}$ & $2(0.33 \%)$ & $1(1.20 \%)$ & $1(0.19 \%)$ & \\
\hline \multicolumn{5}{|c|}{ Education n $(\%)$} \\
\hline Graduate & $319(53.0 \%)$ & $41(49.40 \%)$ & $278(53.60 \%)$ & \multirow{5}{*}{0.8385} \\
\hline Postgraduate & $229(38.0 \%)$ & $35(42.20 \%)$ & $194(37.40 \%)$ & \\
\hline Undergraduate & $34(5.65 \%)$ & $4(4.82 \%)$ & $30(5.78 \%)$ & \\
\hline Other ${ }^{\$}$ & $19(3.2 \%)$ & $3(3.61 \%)$ & $16(3.08 \%)$ & \\
\hline No information & $1(0.2 \%)$ & - & $1(0.19 \%)$ & \\
\hline \multicolumn{5}{|c|}{$\begin{array}{l}\text { BMI=body mass index; } \mathrm{SD}=\text { standard deviation, } \\
\text { p-value is for participants with insomnia versus those without insomnia; paired t-test and chi-square test were used for continuous } \\
\text { and categorical variables, respectively } \\
\text { * Data of one participant was not included as it was an outlier } \\
\text { ' Other includes those separated or widowed } \\
\text { \$Other educational qualifications }\end{array}$} \\
\hline
\end{tabular}

insomnia on working days ( $12.05 \%$ vs. $4.43 \%$, respectively) and holidays ( $9.64 \%$ vs. $5.97 \%$, respectively) (Table 2). Lesser percentage of insomniacs could compensate their sleep on holidays as most of them $(31.33 \%)$ couldn't sleep for more than 8 hours. The difference in duration of sleep between insomniacs and noninsomniacs was statistically significant on working days as well as holidays.

The quality of sleep among insomniacs was significantly affected as compared with non-insomniacs (Table 3). Very few participants with insomnia $(6.02 \%)$ felt that they slept well every night. Numerically higher percentage of participants with insomnia had few and rarely well slept nights as compared to participants without insomnia.

There was a significant difference in the sleep pattern of participants with insomnia and those without insomnia (Table 4). The most commonly reported symptom amongst insomniacs was a feeling of unrefreshing sleep $(87.5 \%)$, followed by a feeling that the sleep was not sound $(71.25 \%)$, difficulty in falling asleep and frequent awakening from sleep $(65 \%$ each), and difficulty in staying asleep $(62.5 \%)$. The percentages are a summative value of 'sometimes', 'frequently', and 'always' responses to a particular symptom. The frequency of all the symptoms experienced in a week was greater in insomniacs as compared with the non-insomniacs.

Participants with insomnia had a significantly higher duration of sleep-related symptoms including difficulty in falling asleep, difficulty in staying asleep, feeling that sleep was not sound, feeling of unrefreshing sleep, and frequent awakenings from sleep compared to participants without insomnia (Table 5).

A significantly higher number of participants with insomnia compared to those without insomnia assumed that their sleep related problem would go away with time $(\mathrm{p}=0.0272)$ (Table 6). Only $4.82 \%$ of insomniacs met or called the family physician for sleep-related problems. Most of the participants with or without insomnia did not take any action for their sleep-related problems, including approximately one fourth of insomniacs $(27.71 \%)$. 


\begin{tabular}{|c|c|c|c|c|}
\hline \multicolumn{5}{|c|}{$\begin{array}{c}\text { Table } 2 \\
\text { Analysis of sleep duration pattern. }\end{array}$} \\
\hline & $\begin{array}{l}\text { All participants } \\
(\mathrm{N}=602)\end{array}$ & $\begin{array}{l}\text { With insomnia } \\
\qquad(\mathrm{N}=83)\end{array}$ & $\begin{array}{l}\text { Without insomnia } \\
\qquad(\mathrm{N}=519)\end{array}$ & p-value \\
\hline & $\mathrm{n}(\%)$ & $\mathrm{n}(\%)$ & $\mathrm{n}(\%)$ & \\
\hline \multicolumn{4}{|c|}{ Sleeping time on working days } & $<0.0001$ \\
\hline Less than $5 \mathrm{~h}$ & $33(5.48 \%)$ & $10(12.05 \%)$ & $23(4.43 \%)$ & 0.5251 \\
\hline 5 to less than $8 \mathrm{~h}$ & $495(82.23 \%)$ & $70(84.34 \%)$ & $425(81.89 \%)$ & $<0.0001$ \\
\hline More than $8 \mathrm{~h}$ & $69(11.46 \%)$ & $3(3.61 \%)$ & $66(12.72 \%)$ & 0.5423 \\
\hline Do not know & $5(0.83 \%)$ & - & $5(0.96 \%)$ & \\
\hline \multicolumn{4}{|c|}{ Sleeping time on holidays } & $<0.0001$ \\
\hline Less than $5 \mathrm{~h}$ & $39(6.48 \%)$ & $8(9.64 \%)$ & $31(5.97 \%)$ & 0.5070 \\
\hline 5 to less than $8 \mathrm{~h}$ & $284(47.18 \%)$ & $49(59.04 \%)$ & $235(45.28 \%)$ & $<0.0001$ \\
\hline More than $8 \mathrm{~h}$ & $276(45.85 \%)$ & $26(31.33 \%)$ & $250(48.17 \%)$ & $<0.0001$ \\
\hline Do not know & $3(0.50 \%)$ & - & $3(0.58 \%)$ & \\
\hline
\end{tabular}

$\mathrm{p}$ value is for participants with insomnia versus without insomnia by the chi-square test

Table 3

Details of quality of sleep.

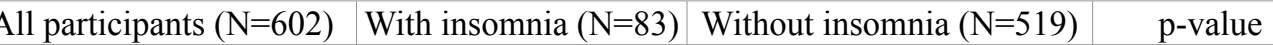
Number of nights perceived well slept, $\mathrm{N}(\%)$

\begin{tabular}{|c|c|c|c|c|}
\hline Every night & $201(33.39 \%)$ & $5(6.02 \%)$ & $196(37.76 \%)$ & 0.1187 \\
\hline Few nights a week & $276(45.85 \%)$ & $37(44.58 \%)$ & $239(46.05 \%)$ & $<0.0001$ \\
\hline Few nights a month & $83(13.79 \%)$ & $25(30.12 \%)$ & $58(11.18 \%)$ & 0.0954 \\
\hline Rarely & $35(5.81 \%)$ & $14(16.87 \%)$ & $21(4.05 \%)$ & 0.4717 \\
\hline Never & $7(1.16 \%)$ & $2(2.41 \%)$ & $5(0.96 \%)$ & 0.8969 \\
\hline
\end{tabular}

$\mathrm{P}$-value is for participants with insomnia versus without insomnia by the chi-square test

\section{DISCUSSION}

The participants in this study were Indian corporate office employees working in the day shift. The primary analysis including the prevalence of insomnia, association of insomnia with co-morbid conditions, impact on work, physical and social performance as well as overall quality of life is reported in a separate publication. The overall prevalence of insomnia was found to be $13.8 \%$. Of these, as high as $96.4 \%$ participants were detected with insomnia by the ISQ, which reiterates the large scale unawareness of insomnia.

The sleep duration pattern was significantly impacted in insomniacs on working days as well as on holidays. A greater percentage of insomniacs had less than 5 hours of sleep as compared with non-insomniacs on working days and holidays. Similarly, a lesser percentage of insomniacs could compensate their sleep on holidays as most of them couldn't sleep for more than 8 hours. On the quality of sleep as assessed by "number of nights perceived well slept", very few participants with insomnia felt that they slept well every night. A higher percentage of participants with insomnia reported to have few (in a month) and rarely well-slept nights as compared to participants without insomnia. This data clearly shows that sleep quality and duration of sleep are affected not only in insomniacs but also in non-insomniacs, more so on the working days. Insomnia with objective short sleep duration ( $<6$ hours) in men is reported to be associated with increased mortality ${ }^{19}$.

There was a significant difference in the sleep patterns of participants with insomnia and those without insomnia. A "feeling of unrefreshing sleep" was the most commonly reported symptom followed by "feeling that the sleep was not sound", "difficulty in falling asleep", and "frequent awakening from sleep". Furthermore, the duration of sleep related symptoms was found to be significantly higher in insomniacs compared with non-insomniacs. Data available from a few studies indicates a widespread presence of sleep problems among the Indian population. A study conducted in a healthy South Indian population reported insomnia in $18.6 \%$ 


\begin{tabular}{|c|c|c|c|}
\hline \multicolumn{4}{|c|}{$\begin{array}{c}\text { Table } 4 \\
\text { Sleep patterns of participants. }\end{array}$} \\
\hline & $\begin{array}{l}\text { With insomnia } \\
\quad(\mathrm{N}=80)\end{array}$ & $\begin{array}{l}\text { Without insomnia } \\
\qquad(\mathrm{N}=516)\end{array}$ & \multirow{2}{*}{$\mathrm{p}$-value } \\
\hline & $\mathrm{n}(\%)$ & $\mathrm{n}(\%)$ & \\
\hline \multicolumn{3}{|c|}{ Difficulty falling asleep } & $<0.0001$ \\
\hline Never & $11(13.75 \%)$ & $233(44.89 \%)$ & 0.0076 \\
\hline Rarely, less than once per week & $16(20.00 \%)$ & $156(30.06 \%)$ & 0.0161 \\
\hline Sometimes, $1-2$ times per week & $16(20.00 \%)$ & $81(15.61 \%)$ & 0.1089 \\
\hline Frequently, 3-4 times per week & $25(31.25 \%)$ & $14(2.70 \%)$ & 0.4294 \\
\hline Always, 5-7 times per week & $11(13.75 \%)$ & $3(0.58 \%)$ & 0.8123 \\
\hline Do not know & $1(1.25 \%)$ & $32(6.17 \%)$ & 0.8121 \\
\hline \multicolumn{3}{|c|}{ Difficulty staying asleep } & $<0.0001$ \\
\hline Never & $9(11.25 \%)$ & $273(52.60 \%)$ & 0.0056 \\
\hline Rarely, less than once per week & $17(21.25 \%)$ & $111(21.39 \%)$ & 0.0458 \\
\hline Sometimes, $1-2$ times per week & $20(25.00 \%)$ & $51(9.83 \%)$ & 0.1648 \\
\hline Frequently, 3-4 times per week & $19(23.75 \%)$ & $9(1.73 \%)$ & 0.5840 \\
\hline Always, 5-7 times per week & $11(13.75 \%)$ & $2(0.39 \%)$ & 0.8462 \\
\hline Do not know & $4(5.00 \%)$ & $72(13.87 \%)$ & 0.4578 \\
\hline Not provided & - & $1(0.19 \%)$ & - \\
\hline \multicolumn{3}{|c|}{ Frequent awakenings from sleep } & $<0.0001$ \\
\hline Never & $15(18.75 \%)$ & $236(45.47 \%)$ & 0.0016 \\
\hline Rarely, less than once per week & $11(13.75 \%)$ & $150(28.90 \%)$ & 0.0530 \\
\hline Sometimes, $1-2$ times per week & $19(23.75 \%)$ & $59(11.37 \%)$ & 0.1431 \\
\hline Frequently, 3-4 times per week & $18(22.50 \%)$ & $16(3.08 \%)$ & 0.4754 \\
\hline Always, 5-7 times per week & $15(18.75 \%)$ & $8(1.54 \%)$ & 0.6481 \\
\hline Do not know & $2(2.50 \%)$ & $50(9.63 \%)$ & 0.6690 \\
\hline Not provided & - & - & \\
\hline \multicolumn{3}{|c|}{ Feeling that your sleep is not sound } & $<0.0001$ \\
\hline Never & $8(10.00 \%)$ & $218(42.00 \%)$ & 0.0312 \\
\hline Rarely, less than once per week & $5(6.25 \%)$ & $121(23.31 \%)$ & 0.2586 \\
\hline Sometimes, $1-2$ times per week & $17(21.25 \%)$ & $77(14.84 \%)$ & 0.1082 \\
\hline Frequently, 3-4 times per week & $20(25.00 \%)$ & $16(3.08 \%)$ & 0.4511 \\
\hline Always, 5-7 times per week & $20(25.00 \%)$ & $4(0.77 \%)$ & 0.7092 \\
\hline Do not know & $10(12.50 \%)$ & $83(15.99 \%)$ & 0.2009 \\
\hline Not provided & - & - & - \\
\hline \multicolumn{3}{|c|}{ Feeling that your sleep is unrefreshing } & $<0.0001$ \\
\hline Never & - & $191(36.80 \%)$ & \\
\hline Rarely, less than once per week & $5(6.25 \%)$ & $153(29.48 \%)$ & 0.1885 \\
\hline Sometimes, $1-2$ times per week & $8(10.00 \%)$ & $96(18.50 \%)$ & 0.2135 \\
\hline Frequently, 3-4 times per week & $38(47.50 \%)$ & $23(4.43 \%)$ & 0.2031 \\
\hline Always, 5-7 times per week & $24(30.00 \%)$ & $3(0.58 \%)$ & 0.7228 \\
\hline Do not know & $5(6.25 \%)$ & $53(10.21 \%)$ & 0.4842 \\
\hline Not provided & - & - & - \\
\hline \multicolumn{4}{|c|}{ P-value is for with insomnia versus without insomnia by the chi-square test. } \\
\hline \multicolumn{4}{|c|}{$\begin{array}{l}\text { of respondents } 5 \text {. Of these, majority had difficulty in initiating and maintaining sleep }(18 \% \text { each), and had } \\
\text { early morning awakening }(7.9 \%)^{5} \text {. In a study conducted in an urban South Indian population, prevalence of } \\
\text { daytime sleepiness was as high as } 59 \%^{20} \text {. In a similar study conducted in Japanese white collar, daytime male } \\
\text { workers, participants with insomnia reported difficulty initiating and maintaining sleep }(11.3 \% \text { and } 14.2 \% \\
\text { respectively) and had early morning awakening }(1.9 \%)^{12} \text {. The prevalence of insomnia, poor sleep quality, } \\
\text { and daytime sleepiness was found to be significantly higher in Iranian shift workers than in the non-shift }\end{array}$} \\
\hline
\end{tabular}


Table 5

Duration of sleep related symptoms reported by participants (in months).

\begin{tabular}{|c|c|c|c|c|}
\hline & All participants & With insomnia & Without insomnia & \multirow[b]{2}{*}{ p-value } \\
\hline & median (range) & median (range) & median (range) & \\
\hline Difficulty falling asleep & $\begin{array}{c}\mathrm{N}=329 \\
5(0.00-420)\end{array}$ & $\begin{array}{c}\mathrm{N}=68 \\
12(0.50-420)\end{array}$ & $\begin{array}{c}\mathrm{N}=261 \\
3(0.00-360)\end{array}$ & $<0.0001$ \\
\hline Difficulty staying asleep & $\begin{array}{c}\mathrm{N}=246 \\
6(0.00-420)\end{array}$ & $\begin{array}{c}N=65 \\
12(0.25-420)\end{array}$ & $\begin{array}{c}\mathrm{N}=181 \\
3(0.00-180)\end{array}$ & $<0.0001$ \\
\hline Feeling that your sleep is not sound & $\begin{array}{c}\mathrm{N}=289 \\
6(0.00-360)\end{array}$ & $\begin{array}{c}\mathrm{N}=62 \\
24(0.25-360)\end{array}$ & $\begin{array}{c}\mathrm{N}=227 \\
4(0.00-144)\end{array}$ & $<0.0001$ \\
\hline Feeling that your sleep is unrefreshing & $\begin{array}{c}\mathrm{N}=355 \\
6(0.00-240)\end{array}$ & $\begin{array}{c}\mathrm{N}=75 \\
24(0.25-240)\end{array}$ & $\begin{array}{c}\mathrm{N}=280 \\
3(0.00-120)\end{array}$ & $<0.0001$ \\
\hline Frequent awakenings from sleep & $\begin{array}{c}\mathrm{N}=300 \\
6(0.00-420)\end{array}$ & $\begin{array}{c}N=61 \\
12(0.25-420)\end{array}$ & $\begin{array}{c}\mathrm{N}=239 \\
4(0.00-120)\end{array}$ & $<0.0001$ \\
\hline
\end{tabular}

Table 6

Details of action taken for sleep-related problems.

\begin{tabular}{|c|c|c|c|c|}
\hline & $\begin{array}{l}\text { All participants } \\
(\mathrm{N}=602)\end{array}$ & $\begin{array}{l}\text { With insomnia } \\
\qquad(\mathrm{N}=83)\end{array}$ & $\begin{array}{l}\text { Without insomnia } \\
\qquad(\mathrm{N}=519)\end{array}$ & p-value \\
\hline Assume it will go away in time & $171(28.41 \%)$ & $32(38.55 \%)$ & $139(26.78 \%)$ & 0.0272 \\
\hline Use over the counter sleep medication & $3(0.50 \%)$ & $1(1.20 \%)$ & $2(0.39 \%)$ & 0.3249 \\
\hline Take already prescribed sleep medication & $14(2.33 \%)$ & $5(6.02 \%)$ & $9(1.73 \%)$ & 0.0160 \\
\hline Meet or call your family physician & $30(4.98 \%)$ & $4(4.82 \%)$ & $26(5.01 \%)$ & 0.9410 \\
\hline Search for solutions over the internet & $15(2.49 \%)$ & $4(4.82 \%)$ & $11(2.12 \%)$ & 0.1429 \\
\hline Seek advice from close friends or family & $44(7.31 \%)$ & $6(7.23 \%)$ & $38(7.32 \%)$ & 0.9759 \\
\hline Never have sleep problems & $173(28.74 \%)$ & $9(10.84 \%)$ & $164(31.60 \%)$ & 0.0001 \\
\hline Nothing & $139(23.09 \%)$ & $23(27.71 \%)$ & $116(22.35 \%)$ & 0.2819 \\
\hline Other & $64(10.63 \%)$ & $14(16.87 \%)$ & $50(9.63 \%)$ & 0.0471 \\
\hline
\end{tabular}

Provided p-value is for the comparison between non-insomniac and insomniac groups.

Chi-squared test was used to calculate the p-value for categorical variables.

workers $^{21}$. The findings of the 2008 National Sleep Foundation Sleep in America poll also showed "feeling of having unrefreshing sleep" as the most commonly reported pattern among insomniac participants, followed by "difficulty falling asleep" and "difficulty staying asleep" 22 .

Our study results showed that only $4.82 \%$ of insomniacs met or called the family physician for sleep-related problems. Most of the participants with or without insomnia did not take any action for their sleep-related problems, including approximately one fourth of insomniacs $(27.71 \%)$. A significantly higher number of participants with insomnia compared to participants without insomnia assumed that their sleep-related problem would go away with time. Patients with insomnia generally do not take any action for their sleep-related complaints ${ }^{7}$. Evaluation of sleep is not the norm in standard practice and should be considered by the general, family, or other primary care practitioner ${ }^{23}$.

Insomnia is generally associated with a host of negative consequences. The part analysis of this study showed that problems related to sleep significantly affect the quality of life in the form of estranged intimate relationships and impairs social functioning as well as leisure time activities. This study has helped to put an insight into the commonly reported sleep patterns among insomniac corporate office employees and a comparison with fellow participants without insomnia. Apart from reporting significant prevalence of undetected insomnia in day time Indian corporate employees, the study results highlight the fact that insomnia is majorly under-reported to the primary physicians. Also, there is a significant decrease in the duration of sleep time and quality of sleep is poor in most of the insomniacs reporting "feeling of an unrefreshing sleep". There is an urgent need to impart knowledge about multidimensional treatment availability in insomniacs, which may help to improve their performance and overall quality of life. It is important to give appropriate attention 
to insomnia in corporate sector employees. In addition, primary care physicians should be encouraged to evaluate sleep as a norm in routine clinical practice.

\section{REFERENCES}

Carskadon MA, Dement WC (2011) Monitoring and staging human sleep. In: Kryger MH, Roth T, Dement WC (Eds). Principles and Practice of Sleep Medicine (5thedn). St. Louis: Elsevier Saunders. 16-26.

Westchester IL (2005) International classification of sleep disorders: Diagnostic and coding manual (2ndedn).

Vgontzas AN, Kales A (1999) Sleep and its disorders. Annu Rev Med. 50: 387-400.

Suri JC, Mehndiratta MM, Bhatia M, Devnani P, Nagpal J, et al. (2014) Consensus statement on the management of Insomnia. Indian Sleep Disorders Association \& Indian Academy of Neurology. Elsevier.

Panda S, Taly AB, Sinha S, Gururaj G, Girish N, et al. (2012) Sleep-related disorders among a healthy population in South India. Neurol India. 60: 68-74.

Morin CM, Leblanc M, Ivers H, Bélanger L, Mérette C, et al. (2014) Monthly fluctuations of insomnia symptoms in a populationbased sample. Sleep. 37: 319-326.

Leger D, Poursain B (2005) An international survey of insomnia: under-recognition and under-treatment of a polysymptomatic condition. Curr Med Res Opin. 21: 1785-1792.

Buysse DJ (2013) Insomnia. JAMA. 309: 706-16.

Moloney MA, Konrad TR, Zimmer CR (2011) the medicalization of sleeplessness: a public health concern. Am J Public Health. 101: 1429-1433.

Utsugi M, Saijo Y, Yoshioka E, Horikawa N (2005) Relationships of occupational stress to insomnia and short sleep in Japanese workers. Sleep 28: 728-735.

Kim HC, Kim BK, Min KB, Min JY, Hwang SH, et al. (2011) Association between job stress and insomnia in Korean workers. J Occup Health. 53: 164-174.

Nakata A, Haratani T, Takahashi M (2004) Job stress, social support, and prevalence of insomnia in a population of Japanese daytime workers. Soc Sci Med. 59: 1719-1730.

Morin CM (2012) Insomnia: prevalence, burden, and consequences. Insomnia Rounds 1: 1-6.

Yardi N, Adsule SA (2015) Cross-Sectional Observational Study to Determine the Prevalence of Insomnia amongst Indian Corporate Employees.

Guilleminault C, Czeisler C, Coleman R, Miles L (1982) Circadian rhythm disturbances and sleep disorders in shift workers. Electroencephalogr Clin Neurophysiol Suppl. 36: 709-714.

Ustun TB, Privett M, Lecrubier Y (1996) Form, frequency and burden of sleep problem in general health care: a report from the WHO collaborative study on psychological problem in general health care. Eur Psychiatry. 11: 5S-10S.

Okun ML, Kravitz HM, Sowers MF, Moul DE, Buysse DJ, et al. (2009) Psychometric evaluation of the Insomnia Symptom Questionnaire: a self-report measure to identify chronic insomnia. J Clin Sleep Med. 5: 41-51.

National Institutes of Health. National Institutes of Health State of the Science Conference statement on manifestations and management of chronic insomnia in adults. Sleep. 28: 1049-1057.

Vgontzas AN, Liao D, Pejovic S (2010) Insomnia with short sleep duration and mortality: the Penn State Cohort. Sleep. 33: 1159-64. 
Roopa M, Deepa M, Indulekha K, Mohan V (2010) Prevalence of sleep abnormalities and their association with metabolic syndrome among Asian Indians: Chennai Urban Rural Epidemiology Study (CURES-67). J Diabetes Sci Technol. 4(15): 24-31.

Yazdi Z, Sadeghniiat-Haghighi K, Loukzadeh Z, Elmizadeh K, Abbasi M (2014) Prevalence of sleep disorders and their impacts on occupational performance: a comparison between shift workers and nonshift workers. Sleep Disord. 2014: 870320.

Swanson LM, Arnedt JT, Rosekind MR, Belenky G, Balkin TJ, et al. (2011) Sleep disorders and work performance: findings from the 2008 National Sleep Foundation Sleep in America poll. J Sleep Res. 20: 487-494.

Pigeon WR (2010) Diagnosis, prevalence, pathways, consequences and treatment of insomnia. Indian Med J Res. 312-332. 